\title{
Borax - an alternative to mercury for gold extraction by small-scale miners: introducing the method in Tanzania
}

\author{
Peter W.U. Appel and Jesper Bosse Jønsson
}

Small-scale mining is extraction of metals, precious stones, industrial minerals and other commodities using simple technologies. At a worldwide scale, an estimated 100 million people depend on income from small-scale mining (Hinton 2006). In Tanzania, there are more than half a million active small-scale miners, most of whom extract gold from placer and hard-rock deposits. Apart from providing a livelihood for thousands of households, small-scale mining reduces migration from rural to urban areas. However, small-scale mining is associated with a number of negative effects, because mining activities have severe impacts on both the local environment and the miners' health. Most significantly the widespread use of mercury for gold extraction results in polluted environments and serious health hazards for the miners themselves and for the population in the vicinity of smallscale gold mining settlements (Bose-O'Reilly et al. 2008a, b; 2010; Jønsson et al. 2009).

Large amounts of mercury are transferred to the environment from small-scale gold mining activities in Tanzania (Taylor et al. 2005). The mercury remains in the environment and constitutes a severe health hazard, also for generations to come. Thus, it is of paramount importance to reduce or, even better, stop the release of mercury from small-scale gold mining. A number of alternative methods have been suggested and tested with limited degrees of success (Hilson \& van der Horst 2002). In 2009 Geocenter Denmark financed a project to test the feasibility of using borax as a replacement for mercury in small-scale gold extraction in Tanzania.

\section{Gold extraction}

Small-scale gold mining of rock deposits in Tanzania is done by sinking shafts and digging tunnels along gold reefs. The mined ore is crushed to walnut size manually or using a jaw crusher and ground in metal drums with hard steel balls or rods, the so-called ball mills. The pulverised material is flushed down a water channel, the bottom of which is covered by a piece of cloth. The heavy particles are caught in the cloth and the light particles end as tailings. This is called sluicing. The heavy fraction from the cloth is treated with mercury (Fig. 1). The gold particles amalgamate with mercury and can thus be separated from other heavy minerals. The amalgam is placed in a small iron cup over a fire, the mercury evaporates and the gold is left behind. This gold extraction method is not efficient, so the tailings from sluicing and amalgamation are reprocessed up to ten times in order to recover more gold. The amalgamation method is easy to learn and swift. However, as mentioned above, the method causes serious environmental and health problems and is not particularly efficient with respect to gold recovery.

Fig. 1. About $100 \mathrm{~g}$ of mercury are added to about $5 \mathrm{~kg}$ of concentrate from the sluicing.

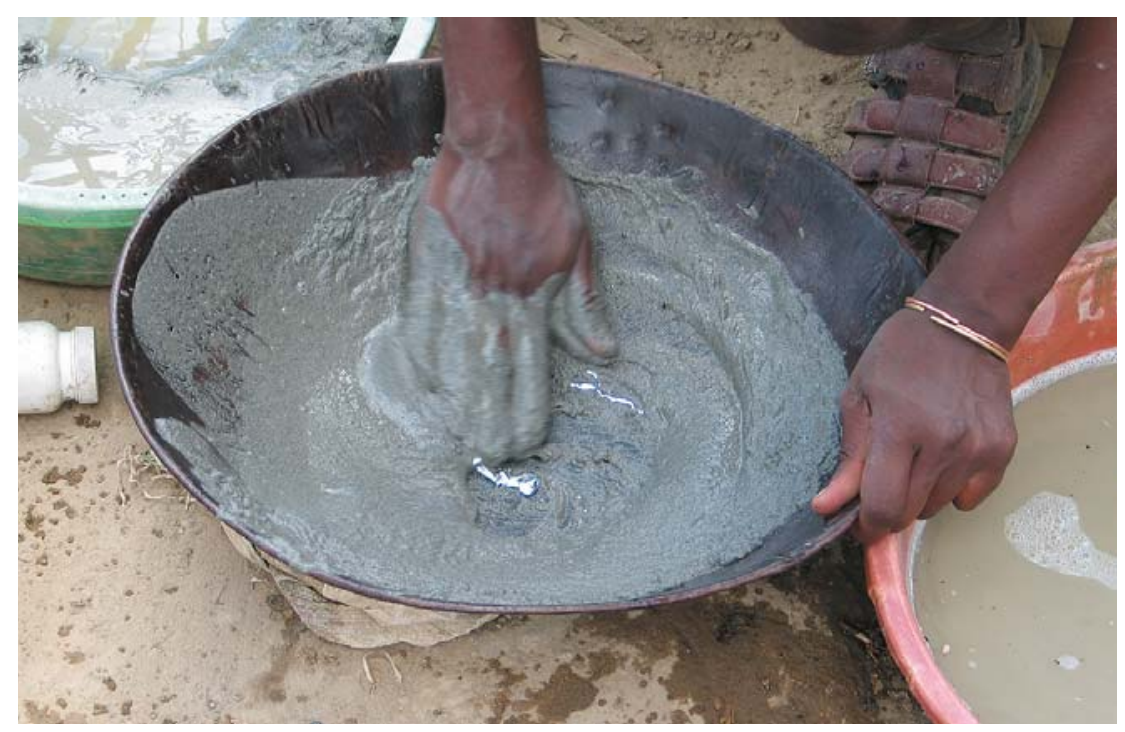




\section{Mercury toxicity}

During amalgamation the metallic mercury evaporates. Some of the vapour is inhaled by people working in the vicinity and may over time cause irreparable damage to their brains. The rest of the mercury vapour gradually precipitates on the ground and enters the drainage system, where it is transformed to methylated mercury by bacteria. Methylated mercury is water soluble and enters the food chain causing serious damage to humans who are at the top of the food chain. Methylated mercury is extremely harmful to the central nervous system, where it causes tremors, difficulty in walking, tunnel vision, psychological problems and eventually death. There is no cure for permanent mercury poisoning (Clarkson et al. 2003).

Unborn babies are especially prone to damage from methylated mercury. If a pregnant mother has mercury in her body, the foetus 'sucks' mercury from her. The nervous system of the foetus is much more sensitive to mercury than that of an adult. A mother with even a low concentration of mercury in her body thus has a high risk of giving birth to mentally or physically disabled children (Davidson et al. 1998).

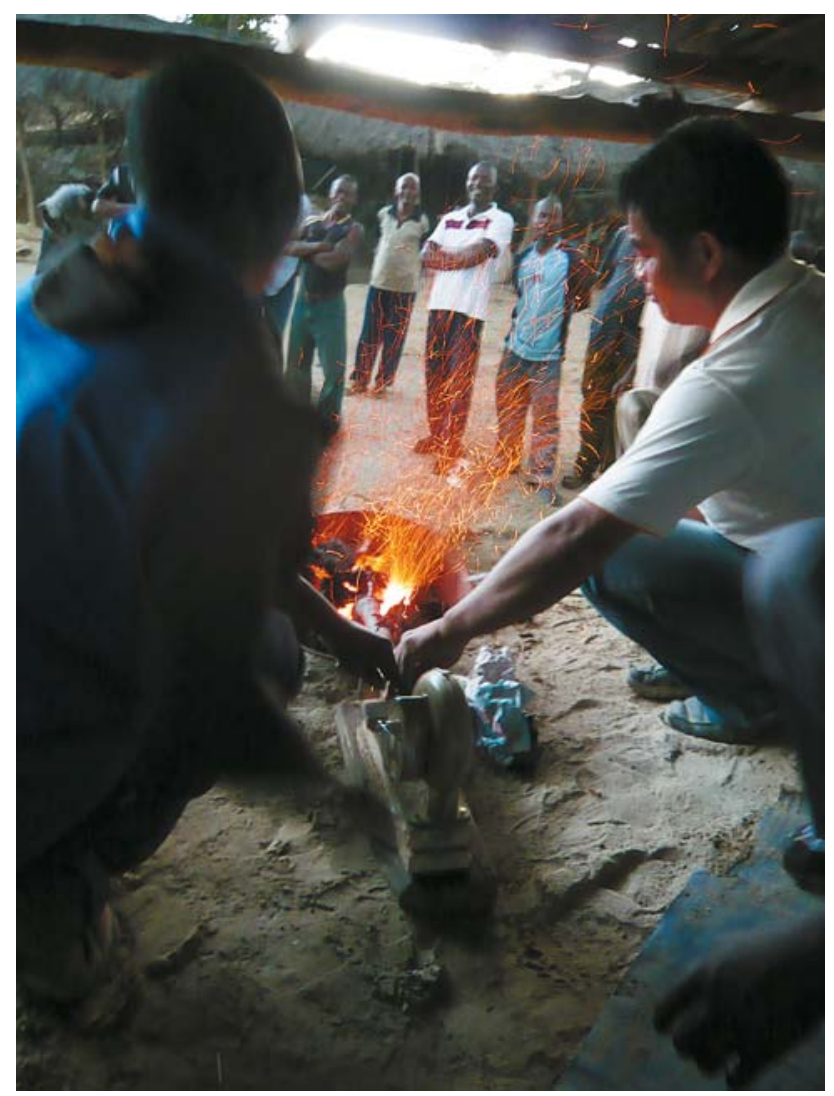

Fig. 2. Vigorous burning of charcoal is achieved with a hand-powered blower.

\section{Gold extraction with borax}

The use of chemical borax, also known as sodium borate, appears to be one of the more viable ways that have been proposed to reduce or stop the use of mercury by small-scale miners (Spiegel \& Veiga 2010). Borax is used for cleaning purposes and is therefore commonly available. The reason for using borax in the smelting process of ore material is that borax reduces the melting point of metals and minerals. Under normal field circumstances small-scale miners cannot smelt gold, as they cannot create the high temperature required to smelt the ore. By adding borax to their concentrate, however, they can extract and smelt their gold.

Gold purchasers already use borax to purify gold with a high content of mercury; however, the method has only recently been applied by small-scale miners. In the Benguet area of the northern Philippines, around 15000 small-scale gold miners currently mix their gold concentrate with borax, followed by heating and smelting (Leoncio $\mathrm{Na}-\mathrm{Oy}$, personal communication 2010). As a consequence, the mercury usage in the area is minimal and the gold recovery rate quite impressive.

The process works as follows: the gold ore is crushed, ground and concentrated as in the case of mercury-based extraction. However, the final product needs to have a very high gold concentration, above $90 \%$, for the borax method to work. This requires skill, practise, and not least time. During testing of the borax method in Tanzania, two ways of smelting gold were applied. The first one involved using charcoal and a blower, the second one the use of acetylene gas.

Charcoal and blower. The gold concentrate is mixed with borax and placed in a plastic bag in a small ceramic bowl filled

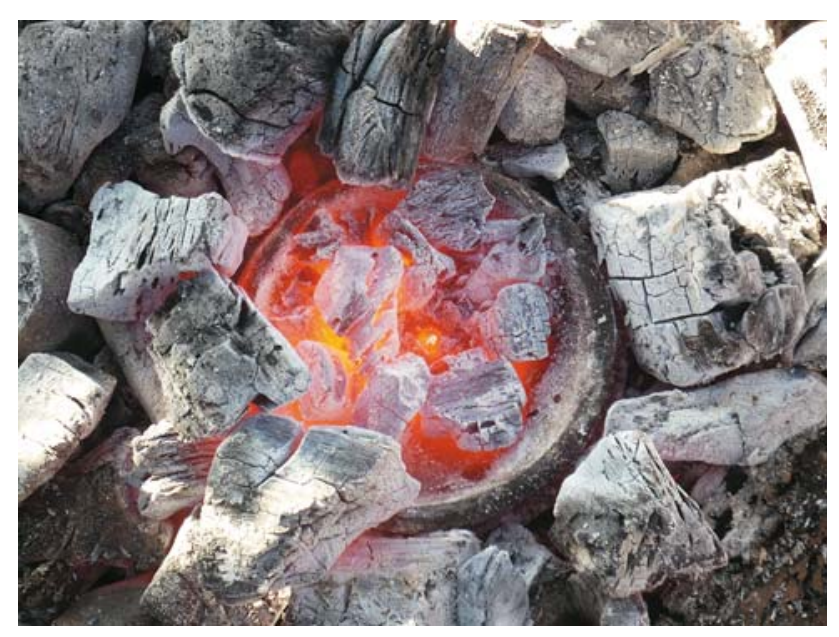

Fig. 3. Molten gold in the centre of the glowing clay bowl and charcoal. 


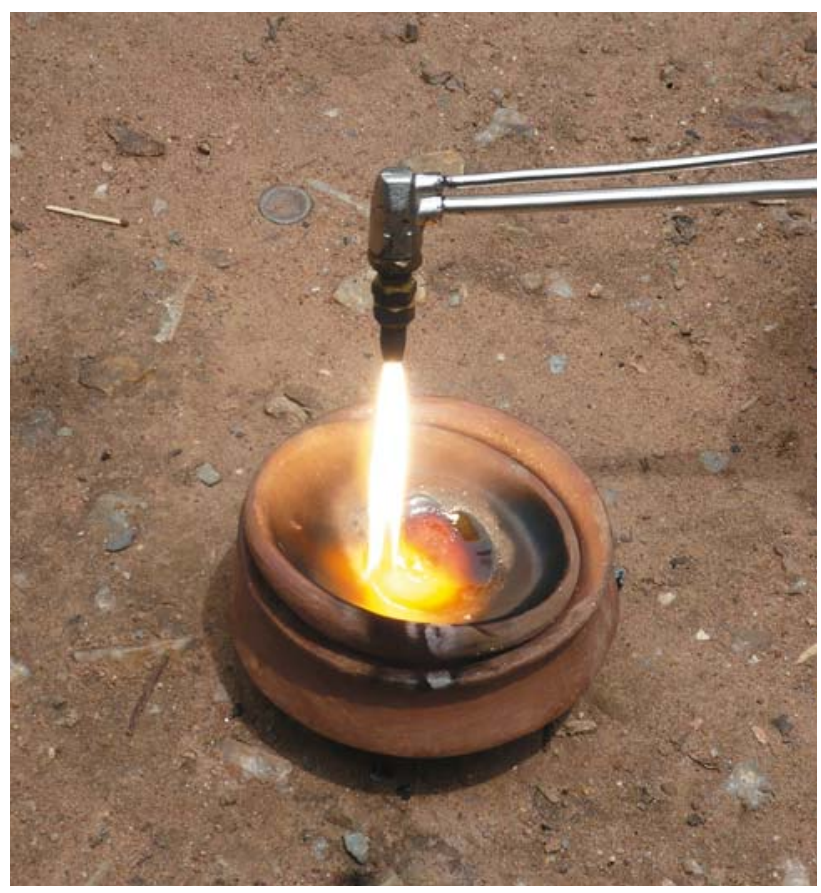

Fig. 4. Gold smelting in borax with an acetylene burner.

with charcoal and some borax, with the recommended ratio between gold concentrate and borax being 1 to 3 . The charcoal is ignited and vigorous burning is achieved by using a hand-powered blower (Fig. 2). After about 30 minutes the metals and minerals in the concentrate begin to smelt and small drops of gold coalesce at the bottom of the bowl (Fig. 3) and can be picked up with the tip of a knife. The advantage of the blower is that it is inexpensive; the disadvantage is that it takes up to half an hour to smelt the gold.

Acetylene gas. The gold concentrate is mixed with borax and placed in a small plastic bag in a ceramic bowl lined with borax. The gold concentrate-borax mixture is melted with the gas flame and after about 10 minutes the gold melts and coalesces (Fig. 4). The advantage of using acetylene gas is that the miners get their gold fast; the disadvantage is that acetylene is expensive and that the gas bottles are heavy to transport.

\section{What does it take for the miners to accept the borax method?}

Changing a well-established habit is difficult and requires very good reasons. The habit of using mercury for gold extraction is clearly such a case, because the mercury method is easy to learn and carry out. Obviously, this makes the introduction of a new and healthier method a challenge, especially because the borax method requires skill and patience.
Depending on the skills of the person who prepares the concentrates, the borax method may take between half an hour and an hour longer than the mercury method.

The immediate advantage of using borax is that it does not harm the environment or the people within or close to the mining sites, in the quantities necessary for gold extraction. In addition, borax is cheaper than mercury and produces purer gold than that produced with mercury (Fig. 5). As small-scale miners are often paid according to the gold content in their gold, the gold produced with borax is likely to provide a better price. However, the question still remains whether these advantages are sufficient to make small-scale gold miners swap from mercury to borax. Considering the embedded culture of using mercury, a change from mercury to borax extraction is not likely to come easy. An additional incentive for the miners to convert to the borax method may be needed.

The Geocenter Denmark project that was conducted in two small-scale mining communities in Tanzania in May 2009 demonstrated that abandoned tailings from small-scale gold mining may contain a very high gold content, with up to $100 \mathrm{ppm}$ of gold. The average gold grade in the ore mined by the small-scale miners is in the order of 3 to $50 \mathrm{ppm}$. It was a puzzle how the miners could loose so much gold in spite of repeated processing. The techniques used by small-scale miners are not sophisticated and in general it is believed that around $50 \%$ of the gold is lost. Nevertheless, tailings with up to $100 \mathrm{ppm}$ gold require an explanation.

When small-scale miners treat their concentrate with mercury, they do not recover all the mercury which instead ends up in the tailings. Miners know that they are incapable of recovering all the gold in one go and therefore reprocess the tailings in the ball mills, where the mercury becomes pounded to an extent where it looses its ability to coalesce; it turns into what may be termed mercury flour. This flour cannot easily be recovered, which also goes for the gold amalgamated with it. As a result, all the mercury-gold flour is lost to the tailing dumps. Awareness by the miners that they lose substantial quantities of gold and income as a result of

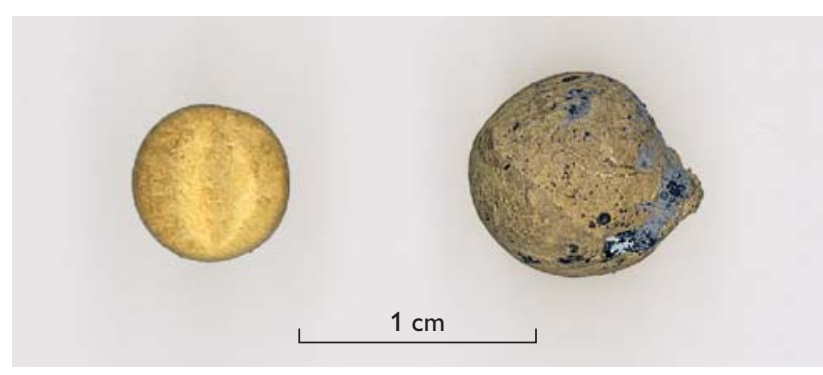

Fig. 5. Gold extracted by borax (left) is pure, whereas gold extracted by mercury (right) contains up to $10 \%$ mercury giving it a paler colour. 
the mercury technique could be what is needed to facilitate a shift from mercury-based to borax-based gold extraction.

\section{Lessons learned in rural Tanzania}

The borax method was tested and demonstrated in the two small-scale gold-mining communities Londoni and Itumbi in Tanzania. The tests were carried out by a small-scale miner from the Philippines, who uses the borax method on a daily basis. In Londoni, a demonstration using charcoal and a blower proved successful and produced a gold tablet of 2.4 grams with a high purity. In Itumbi, the test was carried out by using acetylene gas. The test was successful, a tablet of 3 grams was produced, and the project demonstrated that the method is feasible for small-scale gold miners.

The small-scale miners from Itumbi, a permanent and well-established community, seemed more keen to learn about the mercury-free method than those from Londoni, which is a gold-rush settlement, where most residents come from elsewhere. After the demonstration in Itumbi, the miners expressed their opinion about the method at a small workshop. On the one hand, most miners recognised the potential of using the borax method, as it would significantly reduce mercury usage and improve the purity of their gold. On the other hand, they mentioned the high price of acetylene gas, the fact that borax is not readily available in the region (this is true and ways of making borax available in that part of the country are needed), the longer time required for preparing the concentrate, and the fact that many miners need to process small quantities of gold (e.g. 0.3 gram) on a daily basis to get food on the table, and that the borax method seemed a bit too advanced for such small quantities. Finally, they requested additional instruction and demonstrations in which they could take part before they would be prepared to adopt the new method.

\section{Conclusions}

The borax method was received with interest in both smallscale gold-mining communities, but the attitude was more positive in the more permanent settlement of Itumbi where people are more concerned about the environment. The following points must be taken into account before borax has a chance of replacing mercury: (1) Locally produced, inexpensive blowers or acetylene gas must be easily available, as well as access to the necessary expertise, (2) borax must be readily available, (3) a substantial training programme has to be carried out, (4) a link must be established between the small-scale miners and advisers, preferably the local mining authorities, who can guide the miners when technical problems occur and (5) small-scale miners need to understand the link between the borax method and a higher gold recovery rate.

\section{Acknowledgements}

The authors would like to thank the small-scale miners who participated in the testing of the borax method. Financial assistance for the research was provided by Geocenter Denmark.

\section{References}

Bose-O'Reilly, S., Lettmeier, B., Gothe, R.M., Beinhoff, C., Siebert, U. \& Drasch, G. 2008a: Mercury as a serious health hazard for children in gold mining areas. Environmental Research 107, 89-97.

Bose-O'Reilly, S., Lettmeier, B., Roider, G., Siebert, U. \& Drasch, G. 2008b: Mercury in breast milk - a health hazard for infants in gold mining areas? International Journal of Hygiene and Environmental Health 211, 615-623.

Bose-O'Reilly, S., Drasch, G., Beinhoff, C., Tesha, A., Drasch, K., Roider, G., Taylor, H., Appleton, D. \& Siebert, U. 2010: Health assessment of artisanal gold miners in Tanzania. Science of the Total Environment 408, 796-805.

Clarkson, T.W., Magos, L. \& Myers, G.J. 2003: The toxicology of mercury - current exposures and clinical manifestations. New England Journal of Medicine 349, 1731-1737.

Davidson, P.W. et al. 1998: Effects of prenatal and postnatal methylmercury exposure from fish consumption on neurodevelopment: outcomes at 66 months of age in the Seychelles child development study. Journal of American Medical Association 280, 701-707.

Hilson, G. \& van der Horst, R. 2002: Technology, managerial, and policy initiatives for improving environmental performance in small-scale gold mining industry. Environmental Management 30, 764-777.

Hinton, J.J. 2006: Communities and small scale mining: an integrated review for development planning, $413 \mathrm{pp}$. Washington: World Bank Group.

Jønsson, J.B., Appel, P.W.U. \& Chibunda, R. 2009: A matter of approach: the retort's potential to reduce mercury consumption within small-scale gold mining settlements in Tanzania. Journal of Cleaner Production 17, 77-86.

Spiegel, S.J. \& Veiga, M.M. 2010: International guidelines on mercury management in small-scale gold mining. Journal of Cleaner Production 18, 375-385.

Taylor, H., Appleton, J.D., Lister, R., Smith, B., Chitamweba, D., Mkumbo, O., Machiwa, J.F., Tesha, A.L. \& Beinhoff, C. 2005: Environmental assessment of mercury contamination from the Rwamagasa artisanal gold mining centre, Geita District, Tanzania. The Science of the Total Environment 343, 111-133. 